\title{
Molecular modelling of co-receptor CD8 $\alpha \alpha$ and its complex with MHC class I and T-cell receptor in sea bream (Sparus aurata)
}

\section{Susan Costantini ${ }^{a}$, Francesco Buonocore ${ }^{b}$, Angelo M. Facchiano ${ }^{a, *}$}

\author{
a Laboratorio di Bioinformatica e Biologia Computazionale, Istituto di Scienze dell'Alimentazione - CNR, \\ via Roma 52 A/C, 83100 Avellino, Italy \\ b Dipartimento di Scienze Ambientali, University of Tuscia, Largo dell'Università, 01100 Viterbo, Italy
}

Received 9 January 2008; revised 19 March 2008; accepted 30 March 2008

\author{
KEYWORDS \\ Sparus aurata; \\ Molecular modelling; \\ Protein structure; \\ CD8; \\ T-cell receptor; \\ MHC-I
}

\begin{abstract}
T-cells are the main actors of cell-mediated immune defence; Aney recognize and respond to peptide antigens associated with MHC class I and class II molecules. In this paper, we investigated by molecular modelling methods in the teleost sea bream (Sparus aurata) the interaction among the molecules of the tertiary complex CD8/MHC-I/TCR, which determines the T-cell-Âtediated immunological response to foreign molecules. First, we predicted the three-dimensional structure of CD8 $\alpha \alpha$ dimer and MHC-I, and, successively, we simulated the CD8 $\alpha \alpha / M H C-I$ complex. Finally, the 3D structure of the CD8/MHC-I/TCR complex was simulated in order to investigate the possible changes that can influence TCR signalling events.

(c) 2008 Published by Elsevier Ltd.
\end{abstract}

63 
The $\alpha \beta$ TCRs bind MHC through complementary-determining regions (CDR loops) present in variable domains and are oriented approximately diagonally relative to the long axis of the MHC peptide-binding groove $[6,7]$. The co-receptors CD8 and CD4 stabilize the interaction of the T-cell receptor with MHC-I [8]. In particular, CD8 molecules are expressed as homo- or heterodimers and both chains are composed of an extracellular Ig Vdomain, a membrane-proximal hinge region, a transmembrane domain and a cytoplasmic tail [9] responsible for interaction with a lymphocyte specific kinase (p56lck) [10-12]. CD8 exerts its activity of TCR co-receptor by interacting with $\mathrm{MHC}-\mathrm{I}$ and $\beta_{2}$-microglobulin $\left(\beta_{2}-\mathrm{m}\right)$ during TCR-mediated $M H C$ recognition $[4,13,14]$. Structural studies have shown that CD $8 \alpha \alpha$ associates with $\beta_{2}-m$ and the $\alpha 2$ and $\alpha 3$ domains of $M H C$ using the $A$ and $B$ strands and CDR loops within its $V$ domain. Protein crystallographic studies on human or mouse molecules have investigated the interactions in these binary complexes but no complete system complex, i.e. CD $8 \alpha \alpha / M H C-1 / T C R \beta$, has been yet experimentally characterized.

In teleost fishes CD8, MHC-I and TCR molecules have been recently evidenced. In particular, in sea bream (Sparus aurata) the CD8 $\alpha$ [8], MHC-I $\alpha$ [15], MHC-II $\alpha$ [16] and TCR $\beta$ [17] genes have been cloned. This gives us the possibility to investigate by molecular modelling the $3 \mathrm{D}$ structure of CD8 $\alpha \alpha$, MHC-I and the complexes formed by CD8 $\alpha \alpha / M H C-I$ and CD $8 \alpha \alpha / M H C-I / T C R$. The interaction among the molecules in the complexes has/been analysed in order to study the molecular basis that influences recognition and signalling events.

\section{Methods}

\section{Modelling of sea bream CD8 $\alpha \alpha$ homodimer}

The three-dimensional model of two sea bream CD8 $\alpha 1$ and CD8 22 (EMBL entry: AJ878605.3) chains (see Results and Discussion for motivation) was performed according to the comparative modelling strategy using the template structures of human and murine CD $8 \alpha 1$ (PDB code: $1 \mathrm{AKJ}$, chain $\mathrm{D}$, and $1 \mathrm{BQH}$, chain $\mathrm{H}$ ) and $\mathrm{CD} 8 \alpha 2$ (PDB code: $1 \mathrm{AKJ}$, chain $\mathrm{E}$, and $1 \mathrm{BQH}$, chain $\mathrm{G})$, respectively $[4,5]$.

As the sequence identities between the sea bream chains and the homologous template models were lower than $30 \%$, we used a procedure, already applied and described in previous similar works [17-22], to search for the best alignment of sequences. In detaik, the multiple alignment of many CD8 sequences was made and few manual refinements were added to account for the position of secondary structures. This protocol allows us to improve the alignment of the template and target protein sequences, as well as to avoid the presence of gaps and insertions in secondary structure elements, which are often responsible $\backslash$ for wrong Q2 models.

The MODELLERv7 module [23] implemented in Insight II program (Accelrys, San Diego, CA) was used to build 10 full-atom models of both $\mathrm{CD} 8 \alpha 1$ and $\mathrm{CD} 8 \alpha 2$ chains by setting 4.0 Àas root mean square deviation (RMSD) among initial models and by full model optimization. To select the best models, we used the Prosall program [24] to check the fitness of the sequences relative to the obtained structures and to assign a scoring function, and the PROCHECK program [25] to evaluate their stereochemical and structural packing quality. Secondary structures were assigned by the DSSP program [26]. Search for structural classification was performed on the CATH database $[27,28]$.

The structure of sea bream CD8 $\alpha \alpha$ dimer was assembled by superimposing the two best modelled chains of sea bream CD $8 \propto 1$ and $C D 8 \alpha 2$ to the corresponding murine CD 8 chains, in order to obtain the same relative orientation of the two subunits. The CVFF force field within the Discover module of Insight II was used to assign potentials and charges, and a mild energy minimization was applied, by performing 500 steps under the conjugate gradient algorithm, in order to optimise the interaction between the two sea bream protein chains and avoid sterical clashes according to the procedure used in our previous similar work [29].

\section{D mớdelling of sea bream MHC-I}

The modelling of sea bream MHC-I N-terminal region (20200 amino acid region, accession number: DQ211541.1) was performed using as template the human and murine experimental structures of MHC-I complexed with TCR $\beta$ (PDB code: 2GJ6, chain $A$, and $1 G 6 R$, chain $H$ ) $[2,3]$. The modelling of the $C$-terminal region (201 $\Delta_{295}$ amino acid region, accession number: DQ211541.1) was instead based on the experimental human and murine structures of MHC-I complexed with CD8 $\alpha \alpha$ (PDB code: $1 \mathrm{AKJ}$ chain A, and $1 \mathrm{BQH}$ chain $\mathrm{A})[4,5]$. The sequence identity percentages between sea bream MHC-I and man/mouse resulted in $31 \%$ and 34\%, respectively. The 3D structure of sea bream Q3 MHC-I was modelled and analysed with the same procedures and software described above for CD8.

\section{Simulation of sea bream CD8 $\alpha \alpha /$ MHC-I and CD $8 \alpha \alpha / M H C-I / V \beta$ complexes}

The sea bream CD8 $\alpha \alpha /$ MHC-I and CD $8 \alpha \alpha / M H C-I / V \beta$ complexes were created starting from the reference experimental models of murine CD $8 \alpha \alpha / M H C-I$ [5] and V $\beta / M H C-I$ [4], respectively. In detain, we created the sea bream CD8 $\alpha \alpha / M H C-I$ and $V \beta / M H C-I$ complexes by superimposing the sea bream coordinates on those of murine corresponding molecules in the two available experimental complexes. For the $\mathrm{V} \beta$ (i.e. TCR variable beta) region of the sea bream $\mathrm{T}$-cell receptor (21-240 region, accession number: AM490437) we used the three-dimensional model already described in our recent paper [17]. Moreover, to simulate the sea bream CD8 $\alpha \alpha / M H C-I / V \beta$ complex we superimposed the identical $M H C-I$ chains present in the two sea bream CD8 $\alpha \alpha / M H C-I$ and V $\beta / M H C-I$ complexes. The complexes were minimized using the same procedure described in previous similar works $[15,19,29-32]$. To compare the proteinAprotein interaction in the complexes, the "Protein-Arotein Interaction Server" [33] and the program NACCESS [34] were used to evaluate the interface surface area and to identify the amino acids at the protein-Areceptor interface. H-bonds were calculated with the Hbplus program [35]. Moreover, the binding free energy between the different chains was calculated by using the DCOMPLEX program [36]. 


\section{A}

Human
Mouse
Sea bream
Seabass
Paralichthys
Salmotrutta
Salmosalar
Trout
DanioRerio

Human

Mouse

Sea bream

Seabass

Paralichthys

Salmotrutta

Salmosalar

Trout

DanioRerio

$\begin{array}{cccc}\text { A } & \text { B } & \text { CDR1 } & \text { C } \\ \text { SQFRVSPLDRTWNLGETVELKCOVLLSNPTSGCSWLFQPRGAA-ASPTFLLY }\end{array}$ KPQAPELRIFPKKMDAELGQKVDLVCEVLGS-VSQGCSWLFQNSSSKLPQPTFVVYM TDEVKAVTEGDNAEIKCHPSDPGS - -MI IWFRVRDKSG - - MEFIASF AGEDKATTEGOLVEIHCO - SGTGT - -MIIWFRVLDKTG - - -MEFIGSF GAGELVVKEGAKVDIECKPAEMFN - - TVIWFRVLDNSG - - MEFIASF LSSLTEKTDGERVEITCAPVSKTKSNMVIWFRVQDNAG-- -MEFIASF LSSLTEKTDGKRVEITCAPVSKI KSNMVMWFRVQDNAG - - MEFIASF LSSLTEKTDGERVEITCAPVSKTKSNMVIWFRVODNAG - - -MEFIASE NFANIVYKNGEVVPVDCDPKOPGV - - ITFWFQIKT-SG - - - PKYLFTV

$\begin{array}{llllll}\text { CDR2 } & C^{\prime}, & \text { D } & \text { E } & \text { F } & \text { CDR3 G }\end{array}$ SQNKPKAA- - EGLDTQ-RFSGKRLG-DTFVLTLSDFR RENEGYYFCSALS -NS IMY ASSHNKITWDE KLN SSKLFSAMRDTNNKYVLTLNKFS - KENEGYYFCSVIS -NSVMY SSNGMPKP--NTKSPSSTFIDSKIG--QNILILQSFIEAVD|SGVYSCATLYKGTELR SNNGVLK- - - STSLSNIYROTKIN- - ONILILOSFNKSRDSGIYSCASLYKGNELR GRDGKMKS - - NPSPLSPYIDSSKVD - - KHILTLKSFSKARDSGTYSCT - I IOSNEMK STKDGTK- - - KTDFNNEVFSEEQIN - - KNILILKAFKKARDSGVYSCA - SINGNALV STKDGMK- - KTDFNNEVFSEEQIN - - KNILILKAFKKARDSGVYSCA-SINGNALV STKDGMK- - KTDFNNEVFSEEQIN - - KNILILKAFKKARDSGVYSCA-SINGNALV KGTDVKS - - - - - ITDKEKYIVKTGG - - KVSLAIQSFNKKTDSGFYTCA - AMNNNQLM

Human

Mouse

Sea bream

Seabass

Paralichthys

Salmotrutta

Salmosalar

Trout

DanioRerio

\section{FSHFVPVFLPA \\ FSSVVPVLQKVSSA \\ FGEVTRLVGVK \\ FGKITRLFGEK \\ FGKVTRLIGEK \\ FGEVTRLAGPA \\ FGEATRLAGPA \\ FGEVTRLAGPA \\ FGELTEINGEP}

\section{B}

Human

Mouse

Sea bream

Seabass

Paralichthys

Salmotrutta

Salmosalar

Trout

DanioRerio

B

CDR1 KPOAPELRI FPKKMDAELGQKVDLVCEVLGS-VSOGCSWLFONSSSKLPOPTFVVYM TDEVKAVTEGDNAEIKCHPSDPGS - -MI IWFRVRDKSG - - MEFIASF AGEDKATTEGQLVEIHCQ-SGTGT- -MI IWFRVLDKTG- - MEFIGSF GAGELVVKEGAKVDIECKPAEMFN - - TVIWFRVLDNSG - - MEFIASF LSSLTEKTDGERVEITCAPVSKTKSNMVIWFRVQDNAG-- -MEFIASF LSSLTEKTDGKRVEITCAPVSKI KSNMVMWFRVQDNAG - - MEFIASF LSSLTEKTDGERVEITCAPVSKTKSNMVIWFRVQDNAG - - MEFIASF NFANIVYKNGEVVPVDCDPKOPGV - - ITFWFQIKT-SG - - - PKYLFTV

CDR2 C',

SONKPKAA- D

Human

Mouse

Sea bream

Seabass

Paralichthys

Salmotrutta

Salmosalar

Trout

DanioRerio

F CDR3 G ASSHNKITWDEKLNSSKLFSAMRDTNNKYVLTLNKFS KENEGYYFCSVIS-NSVMY SSNGMPKP--NTKSPSSTFIDSKIG - -QNILILQSFKEAVDSGVYSCATLYKGTELR SNNGVLK- - - STSLSNIYROTKIN - - ONILILOSFNKSRDSGIYSCASLYKGNELR GRDGKMKS - -NPSPLSPYIDSSKVD--KHILTLKSFSKARDSGTYSCT - I IQSNEMK STKDGTK- - KTDFNNEVFSEEQIN - KNILILKAFKKARDSGVYSCA-SINGNALV STKDGMK- - KTDFNNEVFSEEQIN - KNILILKAFKKARDSGVYSCA - S INGNALV STKDGMK- - - KTDFNNEVFSEEQIN - - KNILILKAFKKARDSGVYSCA - S INGNALV KGTDVKS - - - - ITDKEKYIVKTGG - KVSLAIQSFNKKTDSGFYTCA-AMNNNQLM

\section{$\mathrm{H}$}

\begin{tabular}{ll} 
Human & \multicolumn{1}{c}{ H } \\
Mouse & FSHFVPVFLPA \\
Sea bream & FG-SVVPVLQRLV \\
Seabass & FGKITRLFGEK \\
Paralichthys & FGKVTRLIGEK \\
Salmotrutta & FGEVTRLAGPA \\
Salmosalar & FGEATRLAGPA \\
Trout & FGEVTRLAGPA \\
DanioRerio & FGELTEINGEP
\end{tabular}

$\wedge \wedge$

Figure 1 Alignment of CD8 1 (A) and CD8 $\alpha 2$ (B) in human, mouse, sea bream, sea bass, Paralichthys, Salmo trutta, Salmo salar, trout, and Danio rerio. Amino acids in beta-strands are evidenced in grey and those in the $3_{10}$ helix are reported ina box. The labels indicate the $\beta$-strands and CDR loops. 


\section{Results and discussion}

\section{Modelling of sea bream CD8 $\alpha \alpha$ dimer}

The sequence of sea bream $\operatorname{CD} 8 \alpha$ resulted similar to 20 protein sequences, defined as "CD8", from different organisms. The e-values computed by means of the BLAST software resulted in all $<10 \mathrm{e}^{-6}$ and this confirms a signifi-

Q4 cant similarity of these sequences with sea bream CD8 $\alpha$. The percentage of sequence identity between CD8 in sea bream and the other sequences ranged from $59 \%$ to $36 \%$ for teleost fish sequences, and from $33 \%$ to $26 \%$ for mammal sequences. In Fig. 1, we show the alignment of human, mouse, sea bream and other six fish sequences. Human and mouse sequences are of particular interest in our study because the three-dimensional structure of these proteins has Been experimentally solved. On the basis of this knowledge, it is possible to build a theoretical model for the homologous protein from sea bream, by applying the homology modelling strategy or comparative modelling. The reliability of the theoretical models obtained by this strategy is considered very high, but it requires a careful application of a number of software and validation tools as described in the Materials and Methods section. In this case, the experimental three-dimensional structures of human and murine CD8 $\alpha 1$ (PDB code: $1 \mathrm{AKJ}$, chain D, and $1 \mathrm{BQH}$, chain $\mathrm{H}$ ) and $\mathrm{CD} 8 \alpha 2$ (PDB code: $1 \mathrm{AKJ}$, chain $\mathrm{E}$, and $1 \mathrm{BQH}$, chain $\mathrm{G}$ ) have been used for comparative modelling of sea bream CD8 $\alpha 1$ and $C D 8 \alpha 2$. We constructed two CD8 models because these two chains have an identical sequence but may show some conformational differences as reported for experimental murine and human structures. Starting from the alignment of the CD8 sequences (Fig. 1), we created $10 /$ structural models for the $22-128$ region of two sea bream $\operatorname{CD} 8 \alpha$ chains and selected the best models on the basis of stereochemical and energy parameters (see Methods). Both models presen 10 beta-strands (ABCC' $\left.C^{\prime \prime} D E F G H\right)$, involving about $50 \%$ of the sequence and define the global structure as an immunoglobulin-like beta-sandwich made of two anti-parallel sheets. Three loop regions are present between $B$ and $C$ strands (CDR1), between $C^{\prime}$ and $C^{\prime \prime}$ strands (CDR2) and between $F$ and $G$ strands (CDR3). The two cysteines present in $B$ and $F$ strands (Cys 17-Cys85) are at a suitable distance to form an S-8 bond (see Fig. 2), as happens in the template human Q5 and mouse structures [4,5]. These cysteines are conserved in all CD8 sequences from teleost fishes as reported in a recent paper [15]. Moreover, the sea bream CD8 $\alpha 1$ and CD $8 \alpha 2$ models were compared by structural superimposition obtaining an RMSD value of 0.85 A.MThe comparison of secondary structures shows that all $\beta$-strands are quite conserved with some little differences. These evaluations suggest that these two chains have a similar tertiary structure and the differences are located at the level of CDR loops.

The CD8 $\alpha \alpha$ dimer was analysed in terms of interaction residues and interchain $\mathrm{H}$-bond Mumber. The two sea bream CD $8 \alpha$ chains form a dimer that has pseudodyad symmetry according to human and murine dimers. In the CD8 $\alpha \alpha$ dimer one hydrogen bond is formed among Glu115 of CD8 $\alpha 1$ and Thr74 of CD8 $\alpha 2$ and the interface is constituted by 17 and 19 amino acids of $C D 8 \alpha 1$ and $C D 8 \alpha 2$, respectively. In detail,

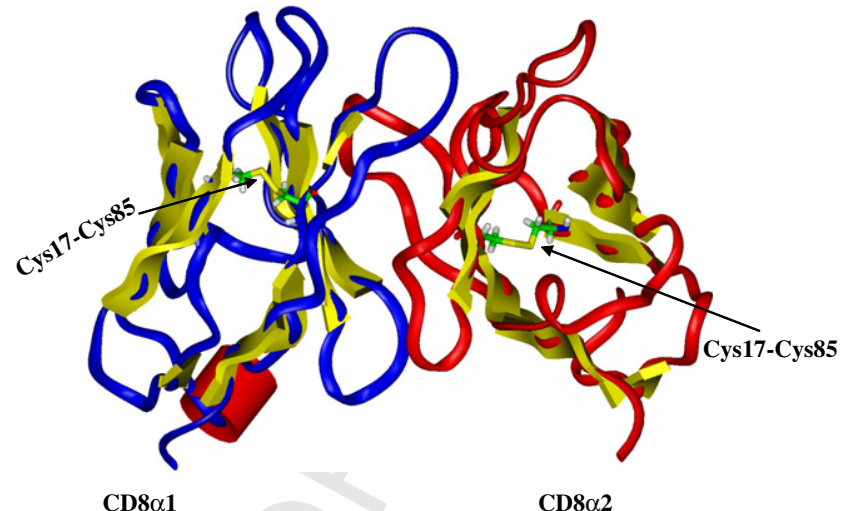

Figure $23 \mathrm{D}$ model of sea bream CD8 $\alpha \alpha$ dimer. The backbone ribbon is reported in blue for CD8 $\alpha 1$ and in red for CD8 $\alpha 2$. $\beta$-Strands are indicated with yellow arrows and helices with red cylinders. Green and yellow sticks indicate the presence of two putative intrachain disulphide bonds.

the dimer interaction in sea bream CD8 $\alpha \alpha$ is mediated by the CDR3-like domain, the $C A C^{\prime}$ loop and the $G$ and $C^{\prime}$ strands as in the human and mouse [37]. Both the $G$ and $C^{\prime}$ strands of this immunoglobulin-like domain contain highly conserved beta-bulges that are found at the dimer interface and are believed to play an important role in facilitating dimerization $[38,39]$. The conserved sequence motifs for the $C^{\prime}$ strand bulge (i.e. ProThrPheLeuLeu and ValVal in human and mouse $\operatorname{CD} 8 \alpha \alpha$, respectively), and for the $G$ strand bulge (i.e. PheSerHisPhe and SerSer in human and mouse $\operatorname{CD} 8 \alpha \alpha$, respectively) are not conserved in sea bream. Moreover, the sea bream CD8 $\alpha \alpha$ homodimer burying aromatic residues, i.e. Trp50, Tyr105 and Tyr111, in the dimer interface shares, as expected, the same dimerization features of human and murine $\operatorname{CD} 8 \alpha \alpha[4,5]$.

\section{D modelling of sea bream MHC-I}

The 3D MHC-I model (Fig. 3) in sea bream has a classical organization in three distinct domains. Two G- $\alpha 1$ [D1] and G- $\alpha 2$ [D2] domains are classified as "alphâ-beta" and each consists of an alpha helical region and four strands of beta sheets in an anti-parallel orientation. The third domain (C-like [D3]) has a "mainly beta" fold and is characterized by an immunoglobulin-like beta-sandwich made of two anti-parallel sheets, each consisting of three main strands and few shorter strands, organized in greek-key motifs. In the sea bream MHC-I model four cysteine residues are located in the same positions of the human and murine templates and they should form two intrachain disulfide bonds in the second and third domains, respectively. The sea bream MHC-I model was compared by structural superimposition with the experimental structures used as templates even if the presence of gaps in the alignment made it difficult to perform a complete structural comparison of the three models. RMSD values obtained comparing the $\mathrm{N}$-terminal regions of human/murine templates complexed with $\mathrm{V} \beta$ and sea bream MHC-I model resulted in $/ 0.79$ and 0.63 A respectively, whether those $\wedge$ obtained for the $\mathrm{C}$-terminal regions of human/murine 


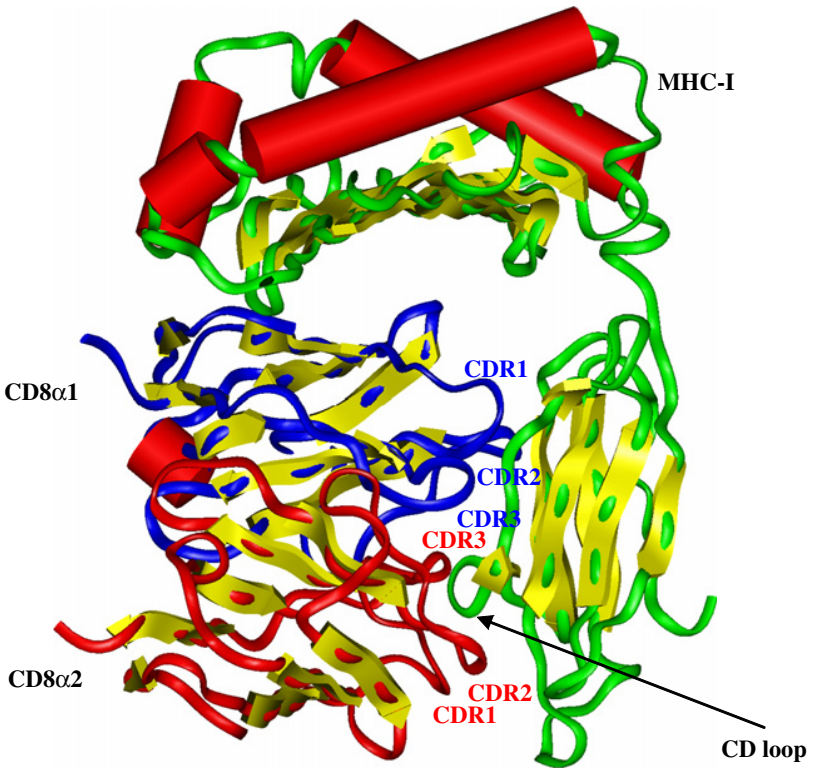

Figure 3 3D model of sea bream MHC-I/CD8 $\alpha \alpha$ complex. The backbone ribbon is reported in green for MHC-I, in blue for CD8 $\alpha 1$ and in red for CD8 $\alpha 2$. Secondary structure topology is shown: yellow arrows represent $\beta$-strands and red cylinders represent $\alpha$ Alelices. Green and yellow sticks indicate the presence of disulphide bonds. The labels indicate the CD loop in MHC-I and three CDR-like loops in the CD8 $\alpha \alpha$ dimer.
Table 1 Analysis of the three complexes in terms of interface surface area $\left(\AA^{2}\right)$, interchain $\mathrm{H}$-bonds and number of interaction residues

\begin{tabular}{|c|c|c|c|}
\hline & $\begin{array}{l}\text { Interface surface } \\
\text { area }\left(\AA^{2}\right)\end{array}$ & $\begin{array}{l}\text { Interchain } \\
\mathrm{H} \text {-bonds }\end{array}$ & $\begin{array}{l}\text { Interaction } \\
\text { residues }\end{array}$ \\
\hline \multicolumn{4}{|c|}{ MHC-I/CD8 $\alpha \alpha$ complex } \\
\hline MHC-I & 605.86 & 6 & 22 \\
\hline $\mathrm{CD} 8 \alpha 1$ & 645.08 & 6 & 18 \\
\hline MHC-I & 665.78 & 9 & 18 \\
\hline $\mathrm{CD} 8 \alpha 2$ & 654.95 & 9 & 18 \\
\hline \multicolumn{4}{|c|}{ MHC-I/CD $8 \alpha \alpha / V \beta$ complex } \\
\hline MHC-I & 609.98 & 6 & 18 \\
\hline $\mathrm{CD} 8 \alpha 1$ & 652.80 & 6 & 16 \\
\hline MHC-I & 686.43 & 9 & 16 \\
\hline $\mathrm{CD} 8 \alpha 2$ & 684.24 & 9 & 14 \\
\hline MHC-I & 634.81 & 7 & 17 \\
\hline $\mathrm{V} \beta$ & 657.61 & 7 & 19 \\
\hline \multicolumn{4}{|c|}{ MHC-I/V $\beta$ complex } \\
\hline MHC-I & 622.88 & 4 & 18 \\
\hline $\mathrm{V} \beta$ & 640.17 & 4 & 18 \\
\hline
\end{tabular}

templates complexed with CD8 and our sea bream model resulted in 0.58 and $0.75 \AA$, respectively. These values indi- Q6 cated that our model keeps the typical architecture of MHC-I in agreement with the structural classification

Table 2 The list of interaction residues between MHC-I, CD8 $\alpha \alpha$ and $\mathrm{V} \beta$ in the three complexes

\begin{tabular}{|c|c|}
\hline MHC-I/CD8 $\alpha \alpha$ complex & Interaction residues \\
\hline \multirow[t]{3}{*}{ MHC-I } & N110,Q114,D121,D126,L127,I133,A134,P135,H208 \\
\hline & $\mathrm{R} 209, \mathrm{~A} 210, \mathrm{~S} 211, \mathrm{~V} 213, \mathrm{E} 220, \mathrm{H} 222, \mathrm{~V} 225, \mathrm{H} 227, \mathrm{G} 228$ \\
\hline & $\mathrm{E} 229, \mathrm{~F} 230, \mathrm{M} 240, \mathrm{Q} 261$ \\
\hline \multirow[t]{2}{*}{$\operatorname{CD} 8 \alpha 1$} & $\mathrm{E} 24, \mathrm{~V} 25, \mathrm{~K} 37, \mathrm{H} 40, \mathrm{P} 43, \mathrm{G} 44, \mathrm{~S} 45, \mathrm{M} 46,148, \mathrm{~S} 65$ \\
\hline & S66,N67,Q88,L110,Y111,K112,G113,L116 \\
\hline \multirow[t]{2}{*}{ MHC-I } & T193,P194,S195,S196,V213,V214,E219,E220,L221 \\
\hline & H222,E223,E224,V225,D226,H227,K245,L246,S247 \\
\hline \multirow[t]{2}{*}{ CD8 $\alpha 2$} & P43,G44,S45,M46,I47,I48,F60,S65,S66,N67,M69 \\
\hline & $\mathrm{P} 70, \mathrm{~K} 85, \mathrm{~T} 109, \mathrm{~L} 110, \mathrm{Y} 111, \mathrm{~K} 112, \mathrm{G} 113$ \\
\hline \multicolumn{2}{|c|}{ MHC-I/CD $8 \alpha \alpha / V \beta$ complex } \\
\hline \multirow[t]{2}{*}{ MHC-I } & Q114,L127,I133,P135,H208,R209,A210,S211,V213 \\
\hline & $\mathrm{E} 220, \mathrm{H} 222, \mathrm{~V} 225, \mathrm{H} 227, \mathrm{G} 228, \mathrm{E} 229, \mathrm{~F} 230, \mathrm{M} 240, \mathrm{Q} 261$ \\
\hline \multirow[t]{2}{*}{$\mathrm{CD} 8 \propto 1$} & $\mathrm{E} 24, \mathrm{~K} 37, \mathrm{H} 40, \mathrm{P} 43, \mathrm{G} 44, \mathrm{~S} 45, \mathrm{M} 46, \mathrm{I} 48, \mathrm{~S} 65$ \\
\hline & S66,N67,Q88,L110,Y111,K112,G113 \\
\hline \multirow[t]{2}{*}{ MHC-I } & P194,S195,S196,V213,V214,E219,E220,L221 \\
\hline & H222,E223,E224,V225,D226,H227,K245,L246 \\
\hline \multirow[t]{2}{*}{$\mathrm{CD} 8 \alpha 2$} & $\mathrm{P} 43, \mathrm{G} 44, \mathrm{~S} 45, \mathrm{M} 46, \mathrm{~S} 65, \mathrm{~S} 66, \mathrm{~N} 67, \mathrm{P} 70, \mathrm{~K} 85$ \\
\hline & $\mathrm{T} 109, \mathrm{~L} 110, \mathrm{Y} 111, \mathrm{~K} 112, \mathrm{G} 113$ \\
\hline \multirow[t]{2}{*}{ MHC-I } & $\mathrm{G} 69, \mathrm{Q} 72, \mathrm{~T} 73, \mathrm{~K} 75, \mathrm{~A} 76, \mathrm{D} 79, \mathrm{Q} 83, \mathrm{I141,K145,W146}$ \\
\hline & D147,N148,N149,K150,G151,L152,L155 \\
\hline \multirow[t]{2}{*}{$\mathrm{V} \beta$} & K46,T48,S49,Y50,Y52,T71,Q72,S73,P74,P75 \\
\hline & Q77,E79,K92,D93,A94,G119,E120,Y101,E122 \\
\hline \multicolumn{2}{|l|}{ MHC-I/V $\beta$ complex } \\
\hline \multirow[t]{2}{*}{ MHC-I } & $\mathrm{G} 69, \mathrm{Q} 72, \mathrm{~T} 73, \mathrm{~K} 75, \mathrm{~A} 76, \mathrm{I78,D79,Q83,I141,K145}$ \\
\hline & W146,D147,N148,N149,K150,G151,L152,L155 \\
\hline \multirow[t]{2}{*}{$\mathrm{V} \beta$} & K46,T48,S49,Y50,Y51,E52,T71,Q72,S73,P74 \\
\hline & P75,Q77,E79,A94,G119,N120,T121,H124 \\
\hline
\end{tabular}


reported by the CATH database $[27,28]$ for the crystallographic structures of human and murine MHC-I molecules. Moreover, the comparison of the secondary structures evidenced that helices and beta-strands are well conserved along the sequence, with just some residue which may increase or decrease their length.

\section{Simulation of sea bream CD8aa/MHC-I complex}

On the basis of the crystallographic structure of the murine CD8 $\alpha \alpha / M H C-I$ complex we simulated the interaction between CD8 $\alpha \alpha$ and MHC-I in sea bream (Fig. 3). For this complex, we evaluated the interaction residues, the number of interchain $\mathrm{H}$-bonds and the interface surface area (Tables 1 and 2). MHC-I and CD8 $\alpha 1$ chains may form six $\mathrm{H}$-bonds at their surface of interaction, while MHC-I and $\mathrm{CD} 8 \alpha 2$ nine $\mathrm{H}$-bonds. The interaction regions between MHC-I and CD $8 \alpha 1 / C D 8 \alpha 2$ in mammalian and sea bream complexes are well conserved (Fig. 4) even if only few amino acids are conserved between fish and mammalian molecules. The CD $8 \alpha 1$ and $C D 8 \alpha 2$ subunits make interactions through their CDR-like loops (CDR1, CDR2 and CDR3) with the $\alpha 3$ domain (C-like [D3]) of MHC-I. Moreover, CD8 $\alpha 1$ interacts also with the $\alpha 2$ domain (G- $\alpha 2$ [D2]) of MHC-I. The major contribution of MHC-I $\alpha 3$ is provided from the protruding loop region (Glu220-Asp226) interacting with

G- $\alpha \mathbf{1}[\mathrm{D} 1]$

\begin{tabular}{|c|c|}
\hline uuman & GSHSMRYFFTSVSRPGRGEPRFIAVGYVDDTQFVRFDSDAASQRMEPRAPWIE- - -QEG \\
\hline & VIAVDSRFGLGEFR MUEVGIVDDIEF VRFDD \\
\hline & THSLKYFYTASSG-VPNFPEFVIVGLVNEVEMFHYDSNTT - -KAEPKQDWMSRVTADI \\
\hline & VTHSLKYFYTASSE-VPNFPEFVVVSMVDGVQMVHYDSNSQ--RAVPKQDWMNKAAEZ \\
\hline & ISLKYFYTASSE-VANFPEFVAVGMVI \\
\hline & \\
\hline
\end{tabular}
$\underset{\text { PEYWDGETRKVKAHSQTHRVDLGTLRGYYNQSEAGSHTVQRMYGCDVGSDWRFLRGYHQ }}{\mathbf{G - \alpha 1} \text { [D1] }}$

human

mouse

sea bream

Salmosalar

Salmotrutta Trout PEYWERETQKAKGNEQSFRVDLRTLLGYYNQSKGGSHTIQVISGCEVGSDGRLLRGYQQ PQYWQRQTEQSVGAQQTF KANIDIAKQRFNQT-GGVHVFQWMYGCEWDDETQEVNGFMQ PQYWDIETGKFLGSHQSFKANIDICKQRFNQS-GGVHVFQKMYGCEWDDEAGATEGLTQ PQYWERETGNCKGSQQNFKANIDIVQQRFNQS-GGVHVFQNMYGCEWDDEAGVTEGFYQ PQYWESQTGNFKGTQQTYKANIDIVKQRFNQS-GGVHIFQRMCGCEWDDEAGVTEGFNQ
G- $\alpha 2$ [D2]

\begin{tabular}{|c|c|}
\hline human & YAYDGKDYIALKEDLRSWTAADMAAAQTTKHKWEA A - HVAEQLRAYLEG TCVEWLRRYL \\
\hline mouse & YAYDGCDYIALNEDLKTWTAADMAALITKHKWERA- GEAERLRAYLEGTCVEWLRRYLK \\
\hline sea bream & YGYDGEDFIAFDLKTLTWIAPKQQAVITKHKWDNNKG LRELRKTYLTR DCGDWVKKYVD \\
\hline Salmosalar & YGYDGEDFIAFDLKTKSXIAPTPQSLITKLKWDSDTAYNEQEKNYLTQICIEWLKKYVL \\
\hline almotrutta & FGYDGKDFIAFDLKTLKWTAPTPQAVITKLKWDSNMAFNEQKKNYLTQICIEWLKKYVI \\
\hline cout & YGYDGEDFIALDLKTTKWIAPTPQAVITKLKWDSNTANTEYWKNYLTQTCIEWLKKYVD \\
\hline & G- $\alpha 2[\mathrm{D} 2]$ \\
\hline Iman & NGGETLQRTDAPKTHMTHHAVSDHEATLRCWALSFYPAEITLTWQRDGEDQTQDTELV \\
\hline buse & NGNATLIRTDSPKAHVTHHSRPEDKVTLRCWALGFYPADITLTWQLNGEELIQDMELVE \\
\hline $\mathrm{a} a \mathrm{~b}$ & YGRSVLIRTELPSVSLLQKTP- - - SSPVSCLATGFYPHRASLVWRKDGEELHEEVDHGE \\
\hline & YGKSTLMRTVPPSVSLLQKTP - - -SSPVTCHATGFYPSGVMVSWQKDGQDHHEDVEYGE \\
\hline & YGKSTLMRTVPPSVSLLQKTP- - -SSPVTCHATGFYPSDVMVSWQKD \\
\hline & IRTVPPSVSLLQKAP - - -SSPVTCHATGFYPRDVMVSWQKDGQDHHEDVEYGI \\
\hline & C-like [D3] \\
\hline suman & TRPAGDGTFQKWAAVVVPSG - - QEQRYTCHVQHEGLPKPLTLRWEP \\
\hline mouse & TRPAGDGTFQKWASVVVPLG - - KEQYYTCHVYHQGLPEPLTLRW \\
\hline sea bream & FLPNHDGTFQMSVDLKLSSVTPEDWTRYDCVFQLSGVNEDIITKLDK \\
\hline Salmosa & TLQNDDGTFQKSSHL - - -TVTPEEWKNNKYQCVVQVTGVKEDFIKVL \\
\hline . & TLPNDDGTFQKSIRL- - - TVTPEEWKNSKYQCVVQVKGLKEDFIKVL \\
\hline & PNDDGTFQKSSHL- - -TVTE \\
\hline
\end{tabular}

Figure 4 Alignment of MHC-I in human, mouse, sea bream, SAllmo salar, SÂlmo trutta and trout. Amino acids in beta-strands are evidenced in grey but those in the helix are reported in a box. Amino acids in bold interact with CD8 $\alpha 1$ and those underlined with Q10 743 $\mathrm{CD} 8 \alpha 2$. The residues at the interface with $\mathrm{V} \beta$ are reported in italics and bold. The labels indicate the different structural domains. 
the $C D 8 \alpha$ subunits by main chain and side chain interactions according to experimental complexes $[40,41]$. In detail, this relatively rigid loop (indicated as loop $\mathrm{CD}$ ) protrudes into the antigen-binding-like pocket formed by the six CDRlike loops of the CD8 $\alpha \alpha$ homodimer. A second distinctive feature essential for the interaction between MHC-I and $C D 8 \alpha \alpha$ is the $A B$ loop of the MHC $\alpha 3$ domain, which interacts with the CDR2-loop of CD8 $\alpha 2$. A third aspect that is characteristic of sea bream MHC-I/CD8 $\alpha \alpha$ complex regards the interaction between the MHC $\alpha 3$ domain and the $\mathrm{N}$-terminal residues of the $\mathrm{CD} 8 \alpha 1$ subunit.

Moreover, the comparison of the specific interaction residues found in sea bream $M H C$-I with respect to other fish species shows that $35 \%$ of the amino acids are conserved as reported in Fig. 4. In the case of $\operatorname{CD} 8 \alpha$ molecules we can note that some structural interactions are in common only within sea bream and sea bass.

There is no significant change in the CD8 $\alpha \alpha$ homodimer structure between the un-complexed versus MHC-I bound state as for human and mouse [4,5]. Finally, it is important to underline that $\beta 2-\mathrm{m}$ interacts with MHC-I and CD $8 \alpha 1$ $[13,14]$ and will influence the interaction between these two chains in the complex. However, the sequence of sea bream $\beta 2-m$ is still unknown, and for this reason we simulated only the interaction between MHC-I and CD8 $\alpha \alpha$. Similarly, the presence of the antigenic peptide in the MHC groove would be useful to simulate the conformation of the MHC molecule when it binds the peptide. Unfortunately, there is no information about the sequence of an antigenic peptide which interacts with MHC class I in sea bream.

\section{Simulation of sea bream CD8 $\alpha \alpha / \mathrm{MHC}-\mathrm{I} / \mathrm{V} \beta$ complex}

The crystallographic studies on $\alpha \beta$ T-cell receptors bound to MHC-I or MHC-II or to TR co-receptors (CD4 and CD8) have $\wedge$ further advanced our knowledge on structural variability of TR/MHC recognition and on the amino acid segments that constitute the TR signalling complex. Despite all these efforts, the structural basis for $\mathrm{MHC}$ restriction and signalling remains elusive and no structural features that define a common binding mode or signalling mechanism have yet been determined. In fact, in the absence of a ternary CD8/MHC-I/V $\beta$ complex structure, no conclusions can yet be drawn to the precise role that the $\mathrm{V} \beta / \mathrm{MHC}$ docking geometry plays in co-receptor binding and downstream signalling [1].

For these reasons, we created a model for $\operatorname{CD} 8 \alpha \alpha$ and $\mathrm{V} \beta$ bound to MHC class I (see Fig. 5). The sea bream $\mathrm{V} \alpha$ sequence was not included in the complex because it is still unknown. Certainly its absence could influence the structure of $V \beta / M H C-I$ complex. However, we modelled the sea bream $V \beta$ using as template the mammalian $V \beta$ structure already complexed with the $\mathrm{V} \alpha$ chain and this gave us the possibility to take into account the $V \beta$ influence on the complex [31]. In fact, using this procedure it is possible to simulate the conformational changes occurring when a protein interacts with its receptor.

The binding sites of CD $8 \alpha \alpha$ and $\mathrm{V} \beta$ to MHC-I are spatially separated even if it is known that they require similar oriQ7 entations with respect to the MHC $\alpha 3$ domain [1]. In detail, $\wedge$ the amino acids of $M H C-I$ at the interface with $\mathrm{V} \beta$ chain are

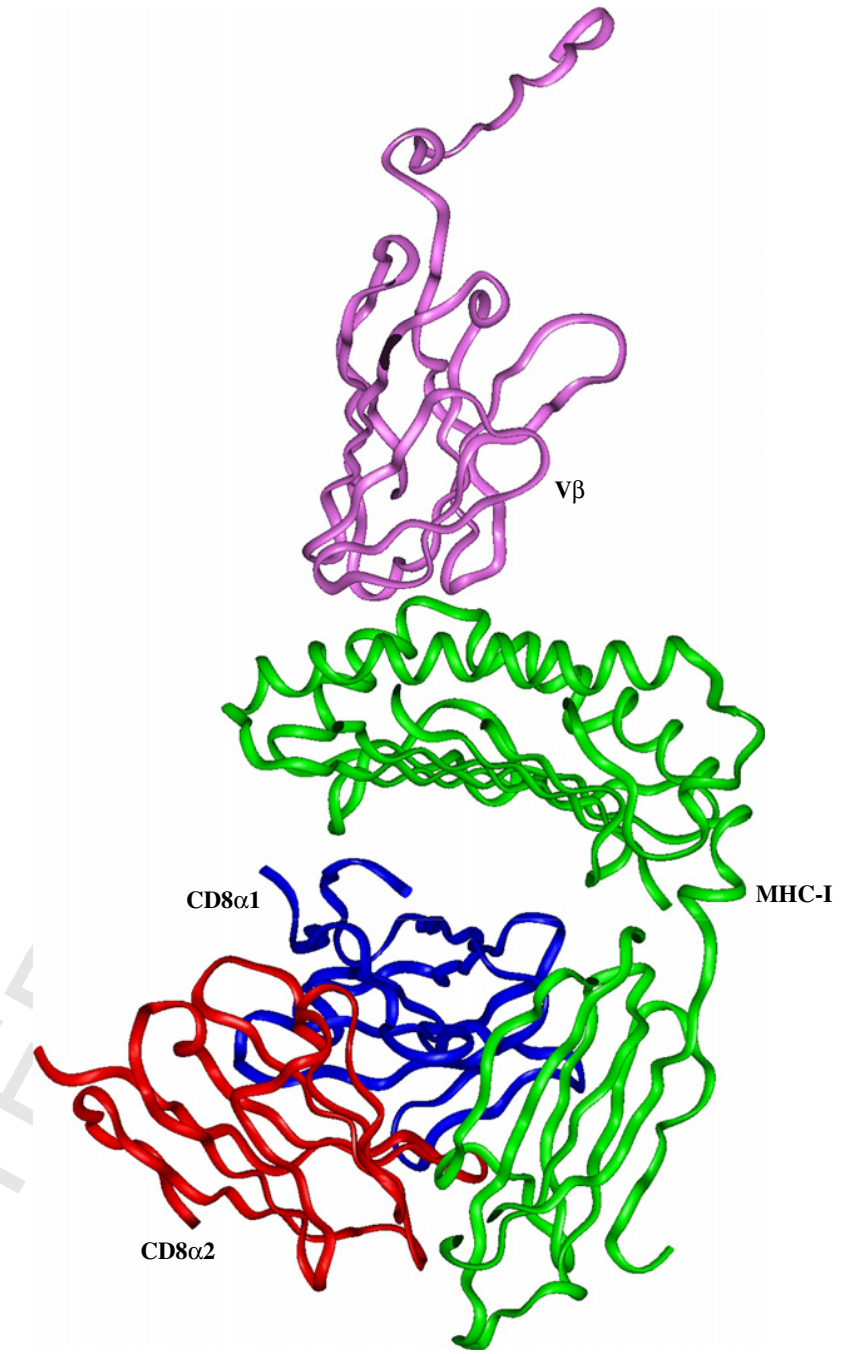

Figure $53 \mathrm{D}$ model of sea bream MHC-I/CD $8 \alpha \alpha / \mathrm{V} \beta$ complex. The backbone ribbon is $A$ ported in green for $M H C-I$, in blue for $\mathrm{CD} 8 \alpha 1$, in red for $\mathrm{CD} 8 \alpha 2$ and in pink for $\mathrm{V} \beta$.

located mainly in helical regions comprised in G- $\alpha 1$ [D1] and G- $\alpha 2$ [D2] domains and those at the interface with CD8 $\alpha \alpha$ are located in loop and beta regions located in G- $\alpha 2$ [D2] and C-like [D3] domains (see Fig. 4).

We compared the two sea bream complexes simulated in this work (i.e. CD8 $\alpha \alpha / M H C-I$, and CD $8 \alpha \alpha / M H C-I / V \beta$ ) and the $\mathrm{MHC}-\mathrm{I} / \mathrm{V} \beta$ recently published [17] in terms of interaction residues, number of interchain $\mathrm{H}$-bonds and interface surface area (Tables 1 and 2 ). These complexes show little differences in the interface surface area values and number of interaction residues.

The number of interchain $\mathrm{H}$-bonds between $\mathrm{MHC}-\mathrm{I}$ and CD8 $\alpha \alpha$ is the same in both CD8 $\alpha \alpha / \mathrm{MHC}-\mathrm{I}$ and CD8 $\alpha \alpha / \mathrm{MHC}-\mathrm{I} /$ $\mathrm{V} \beta$ complexes but taking into consideration $M H C-I$ and $V \beta$ this number is higher in the CD8 $\alpha \alpha / \mathrm{MHC}-\mathrm{I} / \mathrm{V} \beta$ complex with respect to $M H C-I / V \beta$ (see Table 1). Moreover, for each complex we have evaluated the binding energy (Fig. 6) between the different chains. The binding energy between MHC-I and CD8 $\alpha \alpha$ is similar in CD8 $\alpha \alpha /$ MHC-I and CD8 $\alpha \alpha /$ MHC-I/V $\beta$ complexes with a difference of only $0.2 \mathrm{kcal} /$ mol, whether this value between MHC-I and $\mathrm{V} \beta$ is higher
807

808

809

810

811

812

813

814

815

816

817

818

819

820

821

822

823

824

825

826

827

828

829

830

831

832

833

834

835

836

837

838

839

840

841

842

843

844

845

846

847

848

849

850

851

852

853

854

855

856

857

858

859

860

861

862

863

864

865

866

867

868 


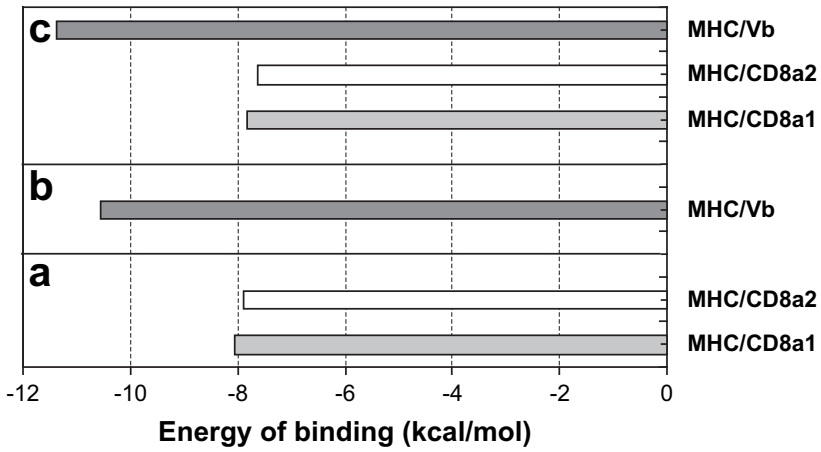

Figure 6 Binding free energies for the complexes. The bars represent the binding energies (expressed in $\mathrm{kcal} / \mathrm{mol}$ ) evaluated for MHC/CD8 $\alpha \alpha$ (panel a), MHC/V $\beta$ (panel b) and MHC/ $\mathrm{CD} 8 \alpha \alpha / \mathrm{V} \beta$ (panel c) complexes.

(of about $0.8 \mathrm{kcal} / \mathrm{mol}$ ) in the CD8 $\alpha \alpha / \mathrm{MHC}-\mathrm{I} / \mathrm{V} \beta$ compared Q8 to $M H C-I / T R \beta$.

These results suggest that the binding of sea bream CD8 $\alpha \alpha$ to MHC-I should increase the affinity of $\mathrm{V} \beta$ for MHC-I and stabilize the $M H C-I / V \beta$ complex. Therefore, the observation that the binding sites of CD8 and TR to MHC-I are spatially distinct but require similar orientations of the MHC $\alpha 3$-domain, is consistent with an avidity-based contribution of the CD8 to the MHC-I-TR binding, as already reported [4].

\section{Conclusions}

Despite the impressive increase in the cloning and expression of genes coding in fish for immunoregulatory molecules, the knowledge on "in vivo" and "in vitro" functional immunology of corresponding peptide products is still at Q9 the beginning. Structural studies could help in improving our knowledge on the behaviour of these molecules until specific markers for immunoregulatory peptides will be available. Moreover, it may be possible to design some peptides, based on the amino acids present at the interface of the modelled complexes, that can block complex formation and that, therefore, should inhibit T-cell activation in vitro and permit interesting functional analyses, as already performed in mammals [42].

\section{Acknowledgements}

This work was partially supported by the CNR-Bioinformatics Project and by the European Commission within the project IMAQUANIM (EC contract number FOOD-CT-2005-007103).

\section{References}

[1] Rudolph MG, Stanfield RL, Wilson IA. How TCRs bind MHCs, peptides and coreceptors. Annu Rev Immunol 2006;24:419-66.

[2] Gagnon SJ, Borbulevvch OY, Davis-Harrison RL, Turner RV, Damirjian $M$, Wojnarowicz A, et al. T cell receptor recognition via cooperative conformational plasticity. J Mol Biol 2006;363: 228-43.

[3] Degano M, Garcia KC, Apostolopoulos V, Rudolph MG, Teyton L, Wilson IA. A functional hot spot for antigen recognition in a superagonist TCR/MHC complex. Immunity 2000;12:251-61.

[4] Gao GF, Tormo J, Gerth UC, Wyer JR, MCMichael AJ, Stuart DI, et al. Crystal structure of the complex between human CD8alpha(alpha) and HLA-A2. Nature 1997;387(6633):630-4.

[5] Kern PS, Teng MK, Smolyar A, Liu JH, Liu J, Hussey RE, et al. Structural basis of CD8 coreceptor function revealed by crystallographic analysis of a murine CD8alphaalpha ectodomain fragment in complex with H-2Kb. Immunity 1998;9(4):519-30.

[6] Garcia KC, Degano M, Stanfield RL, Brunmark A, Jackson MR, Peterson PA, et al. An $\alpha \beta$ T cell receptor structure at 2.5 Angstroms and its orientation in the TCR-MHC complex. Science 1996;274:209-19.

[7] Garboczi DN, Ghosh P, Utz U, Fan QR, Biddison WE, Wiley DC. Structure of the complex between human T-cell receptor, viral peptide and HLA-A2. Nature 1996;384:134-41.

[8] Randelli E, Foglietta A, Mazzini M, Scapigliati G, Buonocore F. Clonino and expression analysis of the co-recptor CD8 $\alpha$ in sea bream (Sparus aurata L.). Aquaculture 2006;256:631-7.

[9] Frazer JK, Capre JD. Structure and function of immunoglobulin. Fundam Immunol 1999;4:37-74.

[10] Veillette A, Bookman MA, Korak EM, Bolen JB. The CD4 and Cd8 $T$ cell surface antigens are associated with the internal membrane tyrosine-protein kinase p56lck. Cell 1988;55:301-8.

[11] Veillette A, Horak ID, Korak EM, Bookman MA, Bolen JB. Alteration of the lymphocyte-specific protein tyrosine kinase (p56lck) during T-cell activation. Mol Cell Biol 1988b;8: 4353-61.

[12] Letourner F, Gabert J, Cosson P, Blanc D, Davoust J, Malissen B. A signalling role for the cytoplasmic segment of the CD8 alpha chain detected under limiting stimulatory conditions. Proc Natl Acad Sci USA 1990;87:2339-43.

[13] Salter RD, Benjamin RJ, Wesley PK, Buxton SE, Garrett TP, Clayberger $\mathrm{C}$, et al. A binding site for the T-cell co-receptor CD8 on the alpha3 domain of HLA-A2. Nature 1990;345:41-6.

[14] Sanders SK, Fox RO, Kavathas P. Mutations in CD8 that affect interactions with HLA class I and monoclonal anti-CD8 antibodies. J Exp Med 1991;174:371-9.

[15] Cuesta A, Meseguer J, Esteban MA. Cloning and regulation of the major histocompatibility class I alpha gene in the teleost fish gilthead seabream. Fish Shellfish Immunol 2007;22(6): 718-26.

[16] Cuesta A, Esteban MA, Meseguer J. Cloning, distribution and up-regulation of the teleost fish MHC class II alpha suggests a role for granulocytes as antigen-presenting cells. Mol Immunol 2006;43(8):1275-85.

[17] Randelli E, Scala V, Casani D, Costantini S, Facchiano A, Mazzini $M$, et al. T cell receptor beta chain from sea bream (Sparus Aurata): molecular cloning, expression and modelling of the complexes with MHC class I. Mol Immunol 2008;45: 2017-27.

[18] Facchiano AM, Stiuso P, Chiusano ML, Caraglia M, Giuberti G, Marra $M$, et al. Homology modelling of the human eukaryotic initiation factor 5A (elF-5A). Protein Eng 2001;14:881-90.

[19] Scapigliati G, Costantini S, Colonna G, Facchiano A, Buonocore $F$, Bossù $P$, et al. Modelling of fish interleukin 1 and its receptor. Dev Comp Immunol 2004;28:429-41.

[20] Buonocore F, Randelli E, Bird S, Secombes CJ, Costantini S, Facchiano A, et al. The CD $8 \alpha$ from sea bass (Dicentrarchus labrax L.): cloning, expression and 3D modelling. Fish Shellfish Immunol 2006;20:637-46.

[21] Buonocore F, Randelli E, Casani D, Costantini S, Facchiano A, Scapigliati G, et al. Molecular cloning, differential expression and 3D structural analysis of the MHC class-II beta chain from sea bass (Dicentrarchus labrax L.). Fish Shellfish Immunol 2007;23:853-66.

[22] Buonocore F, Randelli E, Bird S, Secombes CJ, Facchiano A, Costantini $S$, et al. Interleukin-10 expression by real-time 
PCR and homology modelling analysis in the European sea bass (Dicentrarchus Labrax L.). Aquaculture 2007;270: 512-22.

[23] Sali A, Blundell TL. Comparative protein modelling by satisfaction of spatial restraints. J Mol Biol 1993;234:779-815.

[24] Sippl MJ. Recognition of errors in three-dimensional structures of proteins. Proteins 1993;17:355-62.

[25] Laskowski RA, MacArthur MW, Moss DS, Thornton JM. PROCHECK - A program to check the stereochemical quality of protein structures. J Appl Cryst 1993;26:283-91.

[26] Kabsch W, Sander C. Dictionary of protein secondary structure: pattern recognition of hydrogen-bonded and geometrical features. Biopolymers 1983;22:2577-637.

[27] Orengo CA, Michie AD, Jones S, Jones DT, Swindells $M B$, Thornton JM. CATH - a hierarchic classification of protein domain structures. Structure 1997;5:1093-108.

[28] Pearl FMG, Lee D, Bray JE, Sillitoe I, Todd AE, Harrison AP, et al. Assigning genomic sequences to CATH. Nucleic Acids Res 2000;28:277-82.

[29] Costantini S, Colonna G, Rossi M, Facchiano AM. Modelling of HLA-DQ2 and simulations of its interaction with gluten peptides to explain molecular recognition in celiac disease. J Mol Graph Model 2005;23:419-31.

[30] Chambery A, Pisante M, Di Maro A, Di Zazzo E, Costantini S, Colonna G, et al. Invariant Ser211 is involved in the catalysis of PD-L4, type I RIP from (Phytolacca dioica) leaves. Proteins: Struct Func Bioinform 2007;67:209-18.

[31] Costantini S, Colonna G, Facchiano AM. Simulation of conformational changes occurring when a protein interacts with its receptor. Comput Biol Chem 2007;31(3):196-206.

[32] Gianfrani C, Siciliano R, Facchiano AM, Camarca A, Mazzeo FM, Costantini S, et al. Transamidation of wheat flour inhibits the response to gliadin of intestinal T cells in celiac disease. Gastroenterology 2007;133:780-9.
[33] Jones S, Thornton JM. Principles of protein-protein interactions derived from structural studies. Proc Natl Acad Sci USA 1996;93:13-20.

[34] Hubbard SJ, Campbell SF, Thornton JM. Molecular recognition. Conformational analysis of limited proteolytic sites and serine proteinase protein inhibitors. J Mol Biol 1991;220:507-30.

[35] MCDonald IK, Thornton JM. Satisfying hydrogen bonding potential in proteins. J Mol Biol 1994;238:777-93.

[36] Liu S, Zhang C, Zhou H, Zhou Y. A physical reference state unifies the structure-derived potential of mean force for protein folding and binding. Proteins 2004;56:93-101.

[37] Leahy DJ, Axel R, Hendrickson WA. Crystal structure of a soluble form of the human T cell coreceptor CD8 at $2.6 \AA$ resolution. Cell 1992;68:1145-62.

[38] Chothia C, Novotny J, Bruccoleri R, Karplus M. Domain association in immunoglobulin molecules: the packing of variable domains. J Mol Biol 1985;186:651-63.

[39] Colman PM. Structure of antibody-antigen complexes: implications for immune recognition. Adv Immunol 1988;43: 99-132.

[40] Connolly JM, Hansen TH, Ingold AL, Potter TA. Recognition by CD8 on cytotoxic $T$ lymphocytes is ablated by several substitutions in the class I $\alpha 3$ domain: CD8 and T-cell receptor recognize the same class I molecule. Proc Natl Acad Sci USA 1990;87:2137-41.

[41] Sekimata M, Tanabe M, Sarai A, Yamamoto J, Kariyone A, Nakauchi $\mathrm{H}$, et al. Different effects of substitutions at residues 224 and 228 of MHC class I on the recognition of CD8. J Immunol 1993;150:4416-26.

[42] Quintana FJ, Gerber D, Bloch I, Cohen IR, Shai Y. A structurally altered D,L-amino acid TCRalpha transmembrane peptide interacts with the TCRalpha and inhibits T-cell activation in vitro and in an animal model. Biochemistry 2007;46: 2317-25. 